\title{
Site specific approaches for managing the impacts of ecotourism in Belize, Central America
}

\author{
P. Kumble \\ Department of Landscape Architecture and Environmental Planning, \\ Utah State University, Logan, Utah, USA
}

\begin{abstract}
Demand for ecotourism opportunities has increased dramatically world-wide in recent years. Heightened visitor interest has strained the capacity of ecologically, historically, and archaeologically sensitive sites. In third world countries such as Belize, sensitive sites have suffered from erosion and resource degradation, while local managers, governments and NGO's do not have the monetary or institutional capacity to anticipate, manage and mitigate the unintentional impacts imposed by ecotourists. As such, a framework must be established to identify sites that can sustain their integrity through visitation by ecotourists and locations that should remain closed to visitation by the general public and only used for managed scientific study.

Keywords: visitor impacts, ecotourism, impact assessment, sustainable site design, Belize.
\end{abstract}

\section{Introduction}

The past decade has seen the demand for ecotourism opportunities increase dramatically world-wide. Theoretically, ecotourism is a win-win staple for a developing Central American third-world country such as Belize. Tourists who come from primarily from first-world countries spend money in underdeveloped areas of third world countries, augmenting local economies while receiving varying degrees of goods and services along with a sense of experiential and cultural enrichment. Because this sector of the tourism economy is focused on so-called low-impact locally-run operations, in theory revenue from visitors 
should then flow into the local economy without the attendant negative impacts of traditional mass tourism.

In spite of what would seem to be of economic benefit, the reality is not quite so rosy for the natural and cultural resources that draw visitors to a region; this paper examines those impacts in Belize - formerly know as British Honduras. It proposes an approach for determining a range of treatments, from which ecotourist destination sites should be made available for receiving visitation, to which should be closed to outside visitors and only used for scientific study.

It is an accepted reality that ecotourist visitors are looking for experiences in what they believe to be pristine, natural environments, away from the crowded conditions of conventional tourism sites (Lindberg, et al., [7]). This translates into a desire for undeveloped sites with minimal visitor facilities. However, the impact of the increasing numbers of visitors has strained the ability to sustain the integrity of ecological, historical, and archaeologically sensitive sites. Particularly in third world countries such as Belize, sensitive sites suffer from the wastes, erosion and resource degradation of increasing visitorship, while local managers, governments and NGO's do not have the monetary or institutional capacity to anticipate, manage and mitigate the impacts that ecotourists are inflicting on the sites (Mowforth and Munt, [8]).

\subsection{Economic development vs. resource protection}

To date, research has focused primarily on the economic and social and to a lesser degree the environmental consequences of ecotourism (Mowfort and Munt, [8]; Wall, [10]; Lindberg, et al., [7]). Researchers assert that tourism should achieve both conservation and development goals to be considered as ecotourism (Buckley, [2] as cited in Lindberg, et al., [7]). Ecotourism creates revenue to support protection and management of natural areas, produces an economic benefit for those living adjacent to those natural areas, and supports conservation (Inskeep, [6] as citied in Lindberg, et al., [7]).

In principle, ecotourism promotes preservation and conservation of unique resources by creating an economic demand for those very resources. Social and economic researchers have identified ecotourism as a catalyst for rural development by virtue of its expanded income generation potential (Hearne and Santos, [4]) and it has become the backbone of many Latin American economic development efforts, including the country of Belize.

Despite efforts to foster long-term economic growth and development in many Latin American countries, impacts to sensitive natural and cultural resources from visitors and misinformed government policies threaten to be a significant impediment towards long-lasting sustainable development. Both Harroy [5], and Western and Henry [11], identified national parks as the preferred model for providing protection of wildlife habitat, fostering international tourism, and generating much needed revenue for third-world governments. However, that model overlooks the concerns of local residents and does not re-direct revenue to those populations (Sundbert, [9]), which in theory is counterintuitive to the inferred benefit of ecotourism on local communities. 
Batisse [1] identified the Biosphere Reserve model - developed by the United Nations Educational, Scientific, and Cultural Organization, UNESCO - as an alternative to national parks that could address both environmental and economic needs simultaneously.

The Biosphere Reserve model is based on a desire to incorporate local communities into the process of resource protection. The theory holds that local communities will work to protect those resources from which they gain economic support. While this has been shown to be more or less successful, it is still the role of the governmental or NGO land and resource manager to open protected sites to tourism, and provide the baseline of visitor management and mitigation of impacts to the resource base. In many cases, local land managers are unprepared to decide which model or approach should be applied to locations where there are a mix of cultural artifacts and natural resources - some of which have been identified and others which have not.

Certainly the location of national parks and protected areas in proximity to population centers has an impact on the level of protection they receive (Hearne and Santos, [4]). As such, they often have more extensive facilities to accommodate ecotourists, to manage user needs, and provide the needed mitigation of visitor impacts. However, other areas rich in biodiversity and cultural artifacts that are located in remote or isolated locations are often left without the needed infrastructure to transport visitors, interpret sites, and manage the sites so that they do not become degraded. Hearne and Santos [4] found that remote locations where visitor facilities have not been developed and the staff to implement natural resource management does not exist in sufficient numbers, correlate with a reduction in the percentage of ecotourist expenditures that remain in the local economy. This in turn constrains the income generating potential for local populations and thus reduces their incentive to support conservation of natural areas because they receive little direct benefit for doing so (Hearne and Santos, [4]).

The conflict that exists between preserving the ecological and/or historical integrity of a site by restricting access to the public vs. allowing unfettered tourism is a quandary which is not unique to Belize. Advocates of ecotourism believe it to be ecologically benign and economically profitable (Wall, [10]). Ecotourists desire to visit sites that are typically in isolated locations: part of the allure is that they require a degree of challenge, and in some cases unique skill, to reach. Once there, ecotourists expect to find a site which appears to be pristine with little evidence of human intervention or management. However, allowing even a limited number of visitors to such sites will in many cases alter their character, displace wildlife, and causes site degradation, particularly in the absence of carefully planned site interpretation. Thus, if more sites are made available for visitation, what criteria should be used to protect sensitive natural and cultural features? When and under what circumstances should sites become opened to visitors? To fully answer these questions, in-depth field investigations are necessary at a variety of locations to establish base-line indicators and criteria for measuring sustainability to sensitive natural and cultural features. 


\subsection{Impacts to sensitive resources}

Wall [10] supports the theory that ecotourism has the potential to be disruptive to many of the natural resources which visitors come to see. He rationalizes four principle reasons for this disturbance (Wall, [10]: 1. whereas ecotourism is often directed towards sensitive locations, these locations have limited ability to withstand use pressures; 2 . visitation can occur during critical times of the year (such as during mating or breeding seasons); 3. the assumed relationship between the volume of use at a site and the associated impacts is linear where in fact it is actually step-like (small numbers of users create greater impacts); and 4. although on-site impacts may be slight at some locations, the off-site impacts may also be significant (travel and infrastructure demands to and from destinations).

With increased visitation, the incidence of disturbance of cultural artifacts and impacts from visitors to sensitive natural areas has caused federal land managers in the United States to impose limits on access (Fennell and Dowling, [3]), and to require modest fees for visitation (Lindberg, et al., [7]). For example, park managers at Arches National Park in Moab, Utah have restricted access to certain geological formations due to their fragile structure and damage that has occurred to some landmark formations as a result of extended visitor use. Other federal land management agencies, such as the Bureau of Land Management (BLM), cannot physically restrict access to many of their land holdings rich in archaeological artifacts which date back to native cultural settlement. As such, they have chosen to simply not advertise or provide signage or other wayfinding amenities at many of these locations with greater of lesser results. In addition, site interpretation and facilities have been limited to select locations where visitor impacts can be managed or simply restricted due to physical access constraints.

In many cases, developing third-world countries with extensive collections of archaeological sites and sensitive natural features have not fully recognized the existing or potential for future degradation to sensitive areas, focusing instead on the positive social and economic aspects of ecotourism. This is compounded by the fact that protected sites, encompassing ecological, historic and archaeological resources, are managed by an often overlapping mix of governmental and nongovernmental organizations.

\section{Case study: Belize}

Belize is located in Central America, situated between the eastern boarder of Guatemala and the western side of the Caribbean Ocean (see Figure 1). Belize offers a wide variety of tourism attractions for visitors who come to experience both natural and cultural resources. The Yucatan Peninsula of Mexico is located directly to the north and Honduras immediately to the south. It is similar in size to the state of Massachusetts and has a resident population of approximately 250,000. The landscape is rich with many Mayan sites; Caracol the largest and most significant, is located in the Mountain Pine Ridge region (MPR). Belize 
has significant biodiversity along its coastal frontage on the Caribbean Ocean where the world's second longest barrier reef is located, and on portions of its fresh water interior where aquatic, terrestrial, and avian habitat is predominant.

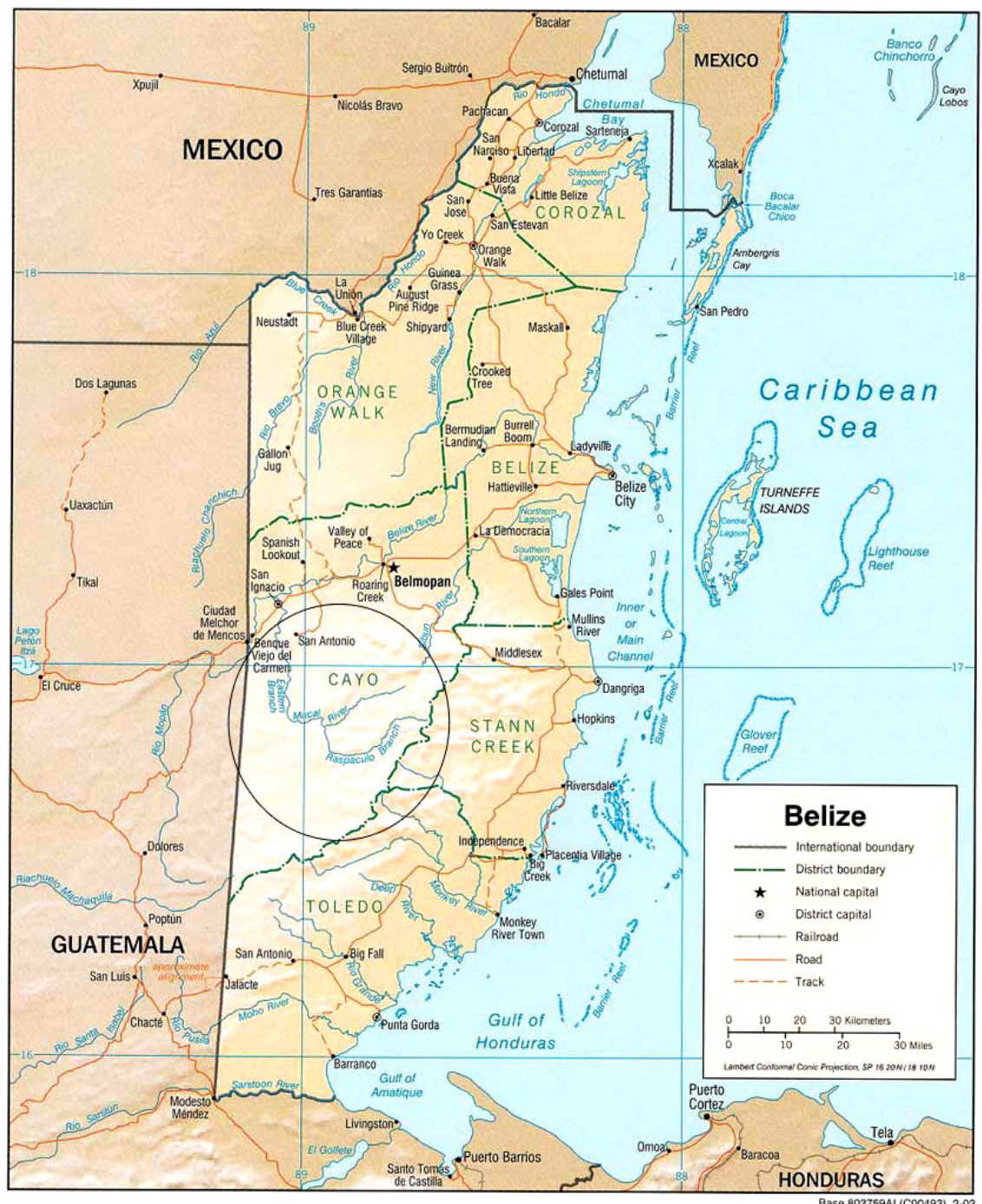

Figure 1: Map of Belize with the Mountain Pine Ridge Region circled.

Although there are three primary population centers - Belize City on the coast, the capital city of Belmopan located approximately 50 miles from the coast, and San Ignacio on the eastern border of Guatemala - much of the country is sparsely populated. As such, the human impact by the resident populations on 
the landscape is slight, leaving what appears to be a pristine natural environment rich in natural features and cultural antiquity; elements which are key to attracting foreign tourists seeking ecotourism experiences. The country has capitalized on these many resources and has placed an emphasis on ecotourism rather than on traditional tourism as the predominant development strategy (Lindberg, et al., [7]). However, with a history of more than two decades of increased ecotourism, the government of Belize has only begun to recognize the need for interpretive facilities, infrastructure, and local vendors who can provide tours to sites in a responsible manner. Yet little attention has been given to the impacts of repeated and prolonged visitation, a prioritization of sites based on the presence of unique, rare, or one-of-a-kind resources.

Whereas the political leadership in Belize desires to see their local economies benefit from increased visitation, there is a lack of resources to manage an increasing influx of visitors to many of the country's cultural and natural sites. Although certain prominent settlements which date back to the Mayan culture are well managed and charge modest entrance fees to support maintenance and facility improvements, other sites receive little management. The monetary limitations on the part of governmental and NGO organizations to effectively manage and mitigate impacts associated with ecotourism are significant. This has resulted in observable site degradation at a number of natural and cultural sites. This is not to say that all sites lack proper care and management, however, the number of locations attractive to visitors simply outnumber the staff and financial resources necessary to care for them. Given the sensitive nature of many sites, should they be opened to the general public?

\subsection{Research findings and recommendations for continued investigation}

Recent field research in the Mountain Pine Ridge region (MPR) of Belize (see Figure 1), spanned a 30-month period and developed site-specific visitor mitigation approaches at a number of locations popular with ecotourists. Sites containing unique and outstanding collections of cultural artifacts, rare and endangered plant species, and critical habitat were inventoried, analyzed and mapped. The four principal locations that were investigated included: a naturally occurring water cascade that flows across a steep series of rock outcropings which support a variety of species of wild orchids; an extensive network of cascading pools and waterfalls which flow into a steep gorge with scenic vistas; a large cave complex which supports a variety of nocturnal species of bat and geological formations; and an isolated cave network containing Mayan artifacts. These sites are typical of destinations visited by ecotourists in the MPR and the country as a whole.

Building upon the four key reasons why ecotourism has the potential to cause environmental impacts to a culturally and environmentally sensitive site as proposed by Wall [10], an initial approach was developed to aid government and NGO land managers to prioritize sites to "formally" open for visitation, and as a method to identify which types of site degradation are most likely to affect the sensitive resources on site. 


\subsubsection{Orchid Cascade}

This site contains a naturally occurring water cascade which flows across a steep rock outcrop. The rock formations support numerous orchid plants, clinging to the rock structure. This site attains its significance from the characteristic geological features, the attractiveness of the rock formations and pools for recreational purposes, and the unusual masses of plants.

At this site, the potential for ecological degradation of the fragile orchid habitat is of greatest concern. The rock formations are extremely attractive to visitors for climbing. The rock surfaces are very slick when wet and the orchids are easily dislodged. Particularly with out proper interpretation, controls on access, and remedial management, this resource is in danger of physical degradation and plant loss due to the action of visitors. Future research in necessary to determine if the orchids are rare or endangered, and if the site is regionally unique or significant.

\subsubsection{Rio-On Pools}

The site is included in all of the tourist guidebooks, and consequently is extremely popular with visitors. It is comprised of an extensive network of cascading pools and waterfalls fed by a small river that is popular for picnicking and bathing, and as a consequence receives large numbers of local tourists, busses of school groups, and ecotourists from around the world. The setting is significant for its water-based recreation and scenic quality.

The water quality of the river has seen degradation due to sedimentation and eutrophication during the period of the study. The sediment has several sources: erosion of the main road, erosion of the parking areas and access roads into the river, exacerbated by potential run-off form the poorly maintained pit toilets. Since the developed trails are poorly maintained and signed, new trails and desire pathways are created by visitors. In addition, the access roads and parking areas are not well stabilized, resulting in significant erosion during periods of heavy rainfall. Given that this site attracts a wide variety of visitors and is well know in the tourist trade - from ecotourists to school children - adequate facilities and pro-active management are necessary to prevent continued degradation to the site.

\subsubsection{Rio Frio Cave}

Since much of the MPR is situated on limestone escarpment, many caves have formed as a result of subsurface groundwater movement. The large cave complex supports a variety of nocturnal species of bat and is located in a semi-isolated setting. The interior surfaces of the cave are covered with a variety of limestone formations.

Similar to Rio-On Pools, Rio Frio Cave has become a popular destination with local tour operators since it is also listed in the major guidebooks of Belize. The cave is accessed via trails leading towards a primary entrance. Site disturbance and degradation occurs from the lack of sanitation, lack of maintenance of the existing sanitary facilities, and human activity on the cave. Human action has significantly damaged the stalagmites and stalactites in the cave. 


\subsubsection{Cave system}

Of the four sites inventoried, one contained a mix of both natural and cultural resources. The cave system is formed of an isolated network of caves containing Mayan pottery and other naturally occurring artifacts such as stalagmites, and orchids, surrounded by highly erodible soils.

Reaching this cave network requires trekking through miles of forest and across steep terrain with the aid of a local experienced guide; no formal or informal trail exists nor is there directional signage. Once reaching the caves, the access to the interior of the caverns is through deep, organic and highly erodible soils. This area is rich in exotic plant species, bird and terrestrial species, nocturnal bat as evident from the large accumulations of guano, and extraordinary cultural artifacts.

Given any level of visitor access, the sites would suffer from significant erosion and loss of vegetation since they would be extremely difficult to stabilize. In addition, without some method of visitor monitoring, the Mayan artifacts present in the caves would be vulnerable to loss.

\subsection{Recommended actions for protection of key resources}

Each of the four locations described above contain significant cultural artifacts and/or exemplary natural features. It is the presence of these character-defining elements which draw ecotourists to the MPR. The challenge remains how to minimize impact and disturbance to these outstanding and unique features while continuing to support growth in the ecotourism industry for Belize. This is the heart of the issue as it pertains to sustainable tourism development.

In order to manage these sensitive sites, and others that have potential for ecotourism, it is necessary to develop an approach to prioritizing the opening of the sites to visitors, followed by a phased approach to site mitigation. A standard landscape architectural approach to problem identification and problem solving provides the basis for this approach:

a. Complete a baseline inventory of the significant flora, fauna and cultural artifacts in the region.

It is clear that each of the four sites located in the MPR contained important cultural and natural resources and because of these characteristics, all are experiencing or will soon attract visitation. What is not known is just how unique and rare are the features at these and other locations in the MPR. Are they commonplace or are they one of only a handful which remains today? To answer these questions, a comprehensive resource inventory is necessary to record and account the variety and range of resources present.

b. By assessing relative ease of access and proximity to existing tourist sites, identify sites with potential for tourism access.

c. Complete an intensive inventory of the significant flora, fauna and cultural artifacts in these areas that are being considered for access to the public. 
d. Compare the resources at these sites to other existing resources, and analyze their relative sensitivity and potential for degradation.

Once the inventory has been completed, an analysis of how sensitive the areas with the greatest potential to attract ecotourists must be undertaken. The intent will be to gauge sensitivity to visitor impacts, such as soils prone to erosion, potentially threatened or endangered plan and animal habitat, and presence of archaeologically important artifacts.

e. Once sites are open to the public, create a regular program of site survey and analysis to identify the early signs of site degradation.

\section{f. Implement mitigation strategies to manage the level of degradation.}

Once the analysis phase has been completed, based on the level or rarity or sensitivity of the identified resources, research will focus on developing programming for key sites. Work will focus on when and under what conditions should sites be opened with minimal visitor impacts. For example, the Mayan cave system would have a high level of visitor interest, but due to limitations on providing access and protection of cultural and natural resources, opening this site up to the public would be difficult without compromising the resources. Rational assumptions will be made to gauge which sites would receive the greatest visitor attraction and make program recommendations for amenities, such as public facilities.

\section{References}

[1] Batisse, M. 1986. Developing and Focusing the Biosphere Concept. Nature and Resources. 22:3. pp. 2-11.

[2] Buckley, R. 1994. A Framework for Ecotourism. Annals of Tourism Research. 21: 661-665. Great Britain: Elsevier Science, Inc.

[3] Fennell, David, A. and Ross K. Dowling. 2004. Ecotourism Policy and Planning. Reviewed in: Annals of Tourism Research, 31:3, pp. 736-737, 2004. Great Britain: Elsevier Science, Inc.

[4] Hearne, Robert, R, and C. A. Santos. Tourists' and Locals' Preferences Towards Ecotourism Development in the Maya Biosphere Reserve, Guatemala. Environment, Development, and Sustainability. 2005. 7: 303318.

[5] Harroy, J.P. 1974. A Century in the Growth of the National Park Concept throughout the World. In Second World Conference on National Parks, edited by H. Elliott, 24-32. Morges, Switzerland: IUCN.

[6] Inskeep, E. 1991. Tourism Planning: An Integrated and Sustainable Development Approach. New York: Van Nostrand Reinhold.

[7] Lindberg, Kreg, Jeremy Enriquez and Keith Sproule. 1996. Ecotourism Questioned: Case Studies from Belize. Annals of Tourism Research. 23:3. pp. 543-562. Great Britain: Elsevier Science, Inc. 
[8] Mowforth, Martin, and Ian Munt. 2005. Tourism and Sustainability: Development and New Tourism in the Third World. Reviewed in: Annals of Tourism Research, 32:2, pp. 499-501, 2005. Great Britain: Elsevier Science, Inc.

[9] Sundbert, Juanita. NGO Landscapes in the Maya Biosphere Reserve, Guatemala. The Geographical Review, 88:3, pp. 388-412. July 1998.

[10] Wall, Geoffrey. 1997. Is Ecotourism Sustainable? Environmental Management, 22:4, pp. 483-491. New York: Springer-Verlag.

[11] Western, D., and W. Henry. 1979. Resident People and National Parks: Social Dilemmas and Strategies in International Conservation. Tucson: University of Arizona Press. 